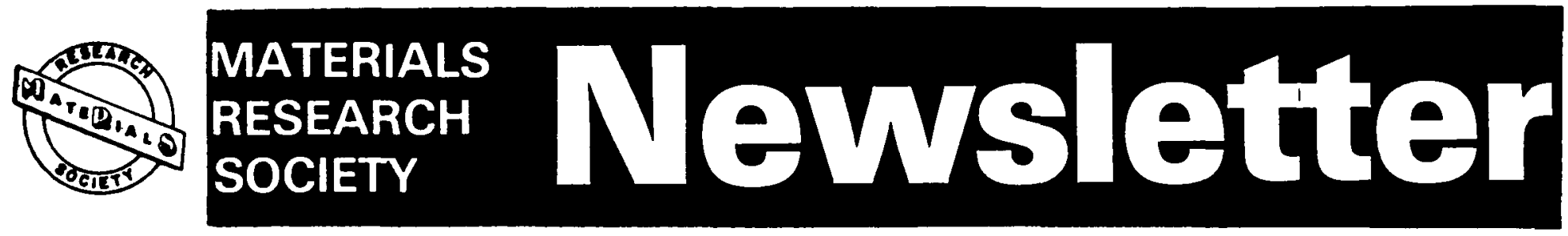

Volume 2, Number 1

May 1976

\title{
CONFERENCE ANNOUNCEMENT AND CALL FOR PAPERS
}

ANNUAL MEETING OF THE MATERIALS RESEARCH SOCIETY

15-17 November 1976, Hyatt Regency, Cambridge, MA

The annual conference of the Materials Research Society will be held at the Hyatt Regency Cambridge Hotel in Cambridge. Massachusetts on 15-17 November 1976. The meeting will consist of six concurrent symposia on the following topics.

CATALYTIC MATERIALS - A symposium covering the materials aspects of catalysis, and emphasizing the overlay between materials and catalysis research.

COMPUTERS IN MATERIALS SCIENCE - This symposium will explore the role of the computer in materials science, especially the use of computers for experiment and process control.

MATERIALS SUBSTITUTION - A symposium on the materials substitution opportunities and potentialities for electrical contacts.

DEFECTS IN MATERIALS - A symposium on defects in crystalline materials, concentrating on growth and process induced defects in semiconductors.

ADVANCED MATERIALS PROCESSINC - This symposium will deal with recent work on molecular beam epitaxy.

NON-CRYSTALLINE SOLIDS - A symposium dealing with amorphous materials, oxide, semiconducting and metallic.

Each symposium will consist of both invited and contributed papers. The conference will provide an opportunity to participate in symposia on a variety of topics of active current interest to the materials research community.

Those interested in contributing a paper to this conference should contact: K. A. Jackson, Bell Laboratories, 600 Mountain Avenue, Murray Hill, New Jersey 07974. Telephone (201) 582-4188.

MATERIALS RESEARCH SOCIETY ANNUAL MEETING

NAME:

ORGANIZATION:

ADDRESS:

TELEPHONE:

1 am interested in attending the conference. Please forward further information as it becomes avai lable.

I plan to contribute a paper. Topic:

Please return this form to Aram Tarpinian. Army Materials and Mechanics Research Center. Watertown. Massachusetts 02172 . 


\section{WASHINGTON WATCH}

\section{Dislocations and Other Defects}

The last few months have put the field of materials in the national scientific news sp.otlight to a hitherto unknown extent. The events with which all should be familiar include:

The Congressional hearings on the Peer Review system held last summer by the Symington (Science, Technology and Research) sub-committee of the House which triggered the question of the "fairness" of the present NSF system of distribution of research funds.

Subsequent to these events some major changes have been made by NSF in many of its procedures including the following:

- Verbatim (unsigned) reviews will be provided on request to the proposer.

- In case of turndown, a standard recourse procedure has been established.

- Open positions are being advertised on a limited scale for the first time.

- Further changes are anticipated, with a possible adoption of the NIH Panel system supported now by NAS President Handler.

The appearance of the detailed COSMAT report of the National Academy with the most extensive set of data on the field and analysis of various problems and opportunities. (See below for some.details.)

Creatly expanded concern about materials resources, and shortages, as evidenced by the activities of the Commission on Shortages and Supplies; the CORRIM study and the joint National Academies of Science and Engineering meeting on Materials and National Development.

\section{Ratings of Departments}

A study by Professor D. Kuhlmann-Wilsdorf of the University of Virginia purporting to show that funds were not equitably distributed by the NSF Division of Materials Research. Materials and Metallurgy section. included an attempt to rate the research quality of materials sciences departments by using the citation index. Related citation index studies were conducted by Johnson and Davis and criticized by Wert and Roy. In the meantime the definitive data, and a rating of the "strength" of materials science departments was presented by the National Academy in its detailed COSMAT REPORT. Page 7-157 carries the following statement.

In an alternative approach to such "peer assessment," the National Science Board" analyzed a variety of physical parameters associated with universities and their relation to the quality of graduate programs. More recently, Elton and Rodgers ${ }^{17}$ have used similar parameters, and argued for a correlation between the quality of graduate physics departments assessed via these parameters and the ranking arrived at by the Roose-Anderson survey. Similar correlations have been suggested by Elton and Rodgers for other scientific fields. These various analyses point to strong correlations between program "size" and program "quality." Such correlation is in keeping with the obvious difficulties of mounting graduate programs of range and depth with only a small faculty. Likewise. a small student enrollment reduces the opportunities for interactive learning that a large student group offers. Small size also may lead to pressures to convert formal courses to individual study or small-group seminars, which are less demanding on the faculty but often a less exacting experience for the student. However, as is well established, some students find that the individual attention they can receive in a small school can be very conducive to high "quality."

.... it is found that the same ten departments occupy the upper-strength regions of both diagrams. In alphabetical order, these schools are:

\author{
University of California (Berkeley) \\ Case Western Reserve University \\ University of Illinois \\ Lehigh University \\ Massachusetts Institute of Technology
}

Northwestern University

Ohio State University

Penn State University

Rensselaer Polytechnic Institute

Stanford University 


\section{Analysis of the MRL's}

The COSMAT report also presents a unique and comprehensive set of data on the interdisciplinary materials research laboratories. For each of the nation's 28 laboratories it presents the volume of research, the faculty involved, the number of students, degrees produced, papers produced, degree of interdisciplinary interaction, the cost of producing a Ph.D. or a paper at each laboratory, etc. etc. Among the surprises in the data is the fact that there is a range of one order of magnitude in many of these costs, a ratio well outside the noise in data which can hardly be precise.

The report is replete with data but appears to want to let the readers draw their own conclusions. No strict "ranking" of laboratories is attempted, instead the report groups the labs as follows:

GROUP A - Major Materials Institutions (MMI) - Institutions which have a materials-center building providing a physical and intellectual focus for major materials research programs, relatively strong centralization of administration, a major degree program in materials, together with strong materials research in solid-state physics and chemistry.

University of California (Berkeley)

Nor thwestern University

Case Western Reserve University

University of Pennsylvania

Cornell University

University of Illinois

Penn State University

Lehigh University

Rensselaer Polytechnic Institute

Massachusetts Institute of Technology

Stanford University

GROUP B - Major Materials-Teaching and Research Schools (MTRS) - Institutions which have a major and/or specialized research program in materials science or engineering and an official through small centralized research laboratory.

University of Connecticut

University of Massachusetts

University of Southern California

University of Missouri

University of Washington

GROUP C - Materials Research Programs (MRP) - Institutions with materials research programs not focused in a centralized laboratory, but often large and typically strong in the basic sciences, and run by a committee of senior faculty, with no (or small) materials-designated degree programs. The term "materials research program", MRP, appears accurately to distinguish the typical characteristics of such centers from the laboratories of the MMI above.

University of Akron
Brown University
University of Chicago
Harvard University
lowa State University
University of Maryland

\author{
University of North Carolina \\ Purdue University \\ Rice University \\ University of Utah \\ University of Washington \\ Washington University (St. Louis)
}

One interesting comparison of the degree of interdisciplinarity of a materials group in a major industrial research laboratory with the University MRL's, shows that academia has still a long way to go if it is to come even with industry.

Similar evaluations by senior materials research managers in government and industry found the MRL's performance above expectation in individual research and training of graduate students; they were judged furthest below expectations in interdisciplinarity of research and in coupling to industry. and slightly too strongly biased towards science rather than engineering. Averages for critical mass effort for a MRL was estimated at 10 man years, and for the optimum block support at $\$ 600,000$. 
Materials Research Society

P.0. Box 1164

Boston, Massachusetts 02103 